\title{
DA RESPOSTA À PREVENÇÃO: INTERFACES ENTRE A GESTÃO DE RISCO DE DESASTRES E O PLANEJAMENTO URBANO
}

\author{
FROM RESPONSE TO PREVENTION: INTERFACES BETWEEN DISASTER RISK MANAGEMENT AND URBAN PLANNING
}

\section{RESUMO}

Nas últimas décadas os desastres têm se tornado uma temática cada vez mais presente no cotidiano das populações das mais variadas regiões, evidenciando um significativo incremento não somente em termos de frequência e intensidade, mas também demonstrando que os impactos causam danos e prejuízos cada vez mais vultosos. O gerenciamento de risco de desastres no contexto nacional historicamente priorizou as ações de resposta, de modo que tanto o processo legislativo quanto as políticas públicas apresentaram características tipicamente reativas, o que, somado ao fato de que a temática em questão foi igualmente negligenciada pela agenda urbana, contribuiu para a vulnerabilidade das cidades brasileiras aos desastres socioambientais. Nada obstante, determinados acontecimentos com aspectos catastróficos que se sucederam na transição da primeira para a segunda década do sec. XXI foram como uma espécie de irritação sistêmica, uma vez que suscitaram uma resposta política que se revelou com a aprovação da Lei Federal no 12.608/2012. A referida legislação em conexão ao Estatuto da Cidade conforma os instrumentos jus-urbanísticos aos princípios da proteção e da prevenção, de modo que a ordenação e controle do uso do solo deve evitar a exposição da população a riscos de desastres. Em que pese o avanço legislativo e a nova reorientação da política urbana, alguns desafios se impõem. A descontinuidade das políticas públicas urbanísticas e os cortes orçamentários são reveses que precisam ser enfrentados para que de fato se alcance a resiliência das cidades.

Palavras-chave: Política urbana. Gestão de risco de desastres. Cidades resilientes.

\section{ABSTRACT}

In the recent decades, disasters have become an even more often present subject in the everyday life of populations from several regions, demonstrating a significant increase not just in terms of frequency and intensity, but also showing the huge damage caused by their impacts. In the national context the disasters risk management, historically, prioritized the action of response, so that even the legislative process or the public policies presented typically responsive characteristics, which added to the fact that the matter in question was equally disregarded by the urban agenda, then been added to the vulnerability of the Brazilian cities to the socioenvironmental catastrophes. However, some events with catastrophic aspects which have succeeded each other in the transition from the first to the second decade of the XXI century were as a sort of systemic irritation, once they have raised a political reply which came out with the approval of the Federal Law no 12.608/2012. The referred legislation in connection with the City Statute conform the urban right means to the principles of protection and prevention, so that the land use ordination and control should avoid the exposure of the population to disasters risk. As subjective as it may be, to the legislative advance and the new urban politics reorientation, some challenges establish themselves. The discontinuity of the urban public policies and the budget cuts are setbacks that need to be confronted so that the cities resiliency can be really achieved.

Keywords: Urban politic. Disasters risk management. Cities resiliency.

\section{Maria Rita Rodrigues ${ }^{a}$}

a Universidade do Estado do Rio de Janeiro (UERJ), Rio de Janeiro, RJ, Brasil

DOI: $10.12957 /$ geouerj.2020.48404

Correpondência: mariarita.rdg@gmail.com

Recebido em: 20 fev. 2019

Revisado em: 19 ago. 2019

Aceito em: 22 ago. 2019 


\section{INTRODUÇÃO}

Mesmo que não existam em território brasileiro registros de grandes terremotos, tsunamis, furacões e até mesmo vulcões, o fato é que outros fenômenos climatológicos, igualmente marcam o território nacional como desastres de elevada magnitude. Neste passo, os fenômenos com os maiores níveis de recorrências estão relacionados a episódios associados a alagamentos, enchentes, inundações bruscas, movimento de massa, além das estiagens e secas.

De acordo com o Atlas Brasileiro para Desastres Naturais (UFSC, 2013), quando se leva em consideração o número de afetados, os desastres mais perversos em razão de seus efeitos à sociedade são a seca e a estiagem. Ao passo que, ao se levar em conta o número de pessoas que vão a óbito, os mais adversos são as inundações bruscas e o movimento de massa, de modo que em função da elevada densidade demográfica, a região com maior número de mortes é o Sudeste.

O ambiente construído, por abrigar grande contingentes populacionais, quando palco de enchentes e deslizamentos de encostas, constitui-se como o espaço cujas consequências são mais drásticas. Neste contexto, não obstante em um primeiro momento os desastres serem qualificados como naturais, não se pode olvidar que alguns fatores contribuem de forma decisiva para o aumento e a intensidade de sua ocorrência, dentre os quais cabe destacar as formas, em grande medida, de apropriação do solo urbano. Assim, relevante se faz qualificar os desastres como socioambientais, com vistas a promover a necessária articulação entre os fatores naturais e as causas antropogênicas.

São os significativos obstáculos no que tange à compilação de dados acerca de desastres socioambientais no Brasil, uma vez que não há procedimento padronizado seja para a coleta e armazenagem de dados, seja na própria apresentação dos documentos. O histórico de ocorrências de desastres demonstra que de fato, o Brasil não é imune aos eventos da natureza, notadamente aqueles cujos efeitos mais drásticos se articulam com a atuação ou omissão oriunda da atividade humana.

Na última década, a temática dos desastres, até então chamados naturais, tem ganhado envergadura entre os mais diversos âmbitos da sociedade, bem como tem se enveredado como uma dimensão significativamente importante, embora ainda incipiente, da política urbana no Brasil. De fato, o gerenciamento de risco de desastres foi marcado por um caráter reativo, eis que as tomadas de ações públicas, e o processo legislativo em matéria de gestão de risco, em regra, ocorriam após a incidência de uma catástrofe.

Além do enfoque da gestão de risco de desastres tradicionalmente concentrar-se por demasiado nas ações de respostas, não é possível constatar uma articulação satisfatória entre a temática e sua necessária interface na política urbana. O que não há como se negar é algo no mínimo contraditório, já que o processo de urbanização brasileiro é marcado pela insuficiência na promoção de moradia para todos os estratos sociais, 
aliado a um inepto ordenamento territorial que favoreça o interesse social, o que implicou na vulnerabilidade das cidades aos desastres.

E embora o arcabouço normativo brasileiro já conte com instrumentos legislativos, que em alguma medida abordam a temática dos desastres, o marco legal acerca da referida questão consagrou-se no ano de 2012, através da Lei Federal no 12.608. A norma reestruturou toda a conformação do Sistema Nacional da Defesa Civil, de forma a primar pelo paradigma da prevenção e proteção, trilhando um caminho em certo sentido diferente do que até então se praticava, já que as condutas até então traquejadas estavam mais direcionadas para a frente da resposta.

Lado outro, o recente marco legal tem como um de seus objetivos a integração da gestão de riscos às mais variadas políticas setoriais, dentre as quais merece destaque as políticas de ordenamento territorial e desenvolvimento urbano. Assim, evidencia-se o liame entre a Lei no 12.608/2012, que institui a Política Nacional de Proteção e Defesa Civil, e a Lei no 10.257/2001, o Estatuto da Cidade. A conexão entre ambos os marcos regulatórios traça uma nova diretriz que caracteriza a política urbana na segunda década do XXI em termos de gestão de risco de desastres, que é a de que a ordenação e controle do uso do solo deve evitar a exposição da população a riscos de desastres. Para tanto, além de primar os elementos proteção e prevenção, novos instrumentos de política urbana, como as cartas geotécnicas de aptidão à urbanização, podem auxiliar os instrumentos jus-urbanísticos já existentes, a fim de fomentar o equilíbrio urbano, a sustentabilidade urbano ambiental e a construção de cidades resilientes.

\section{O cenário urbano nacional frente à ocorrência de desastres}

É possível perceber que nos últimos anos os acontecimentos referentes aos desastres que acometem o território brasileiro têm ganhado destaque tanto nos mecanismos de difusão de informação e comunicação, quanto em termos de políticas públicas. Isso porque nas últimas décadas os desastres têm se tornado uma temática cada vez mais presente no cotidiano das populações das mais variadas regiões, evidenciando um significativo incremento não somente em termos de frequência e intensidade, mas também demonstrando que os impactos causam danos e prejuízos cada vez mais vultosos.

Não obstante a dificuldade histórica que o Sistema de Defesa Civil tem no sentido de manter um cadastro atualizado dos seus registros, o Atlas Brasileiro de Desastres Naturais - fruto da articulação conjunta entre a Secretaria Nacional da Defesa Civil e o Centro Universitário de Estudos e Pesquisas sobre Desastres da Universidade Federal de Santa Catarina - produziu informações acerca dos registros de desastres ocorridos no território nacional, no período que compreende os anos de 1991 até 2012 (UFSC, 2013). Os dados 
produzidos pela pesquisa corroboram com o frequente discurso acerca do aumento da ocorrência de desastres.

A análise dos dados do Atlas permite diversos cruzamentos, bem como uma abordagem através de diferentes aspectos, sendo extremamente útil e profícuo aos gestores públicos nos processos de tomada de decisão e na formulação de políticas públicas que perpassam o tema. Contudo, inobstante às dificuldades metodológicas enfrentadas pelos pesquisadores no que tange a coleta de dados, cumpre destacar o aumento da frequência da ocorrência de desastres na transição da primeira para a segunda década do século XXI, conforme demonstra a Figura 1.

Figura 1. Desastres naturais no Brasil (percentual em relação ao total de eventos registrados no período 1991-2012). Fonte: Atlas brasileiro de desastres naturais (UFSC, 2013).

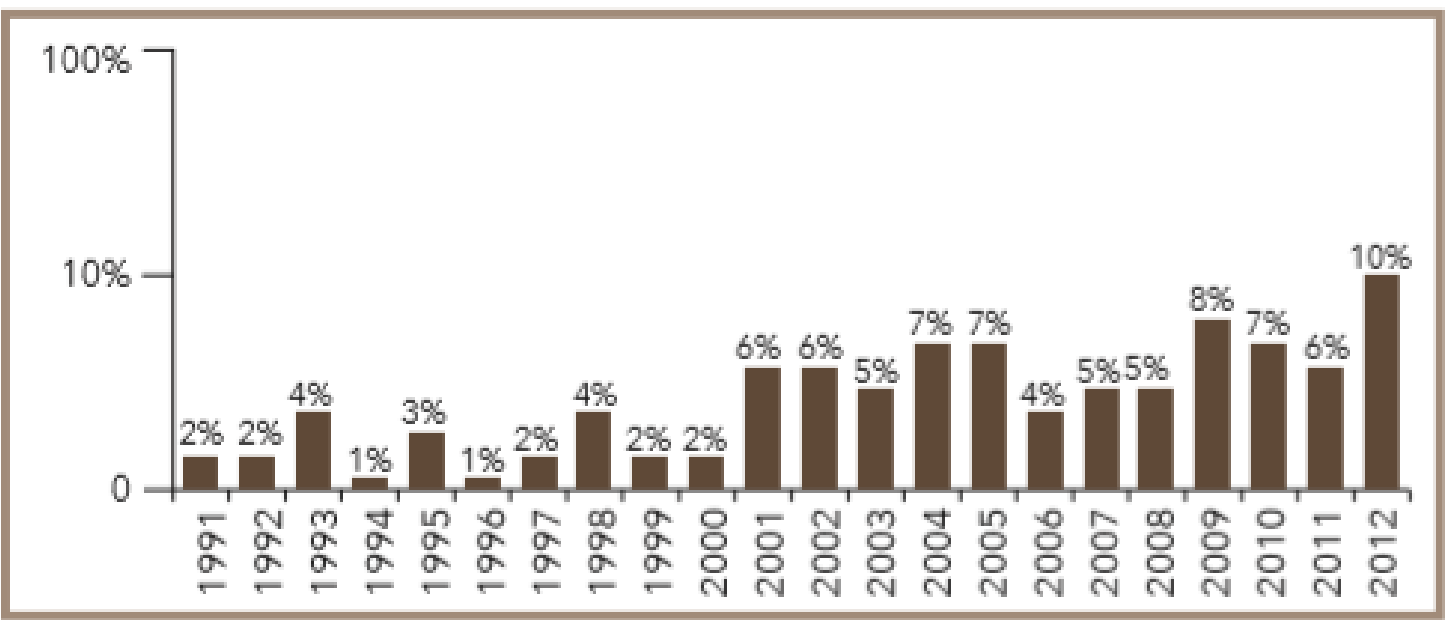

Além disso, destaca-se o potencial de amplificação dos desastres em território brasileiro, pela observação e análise da Figura 2 - que apresenta a diferença de registros por tipo de desastres entre as décadas de 1990 e 2000. Para efeitos de comparação, percebe-se que o aumento de episódios envolvendo movimento de massa é sobremaneira significativo. Trata-se do fenômeno que mais teve variação entre as décadas, com aumento de 21,7 vezes, em contraponto à média geral relativa a outros fenômenos, que é de seis vezes. (UFSC, 2013). 
Figura 2. Comparativo de ocorrência entre décadas. Fonte: Atlas brasileiro de desastres naturais. (UFSC, 2013).

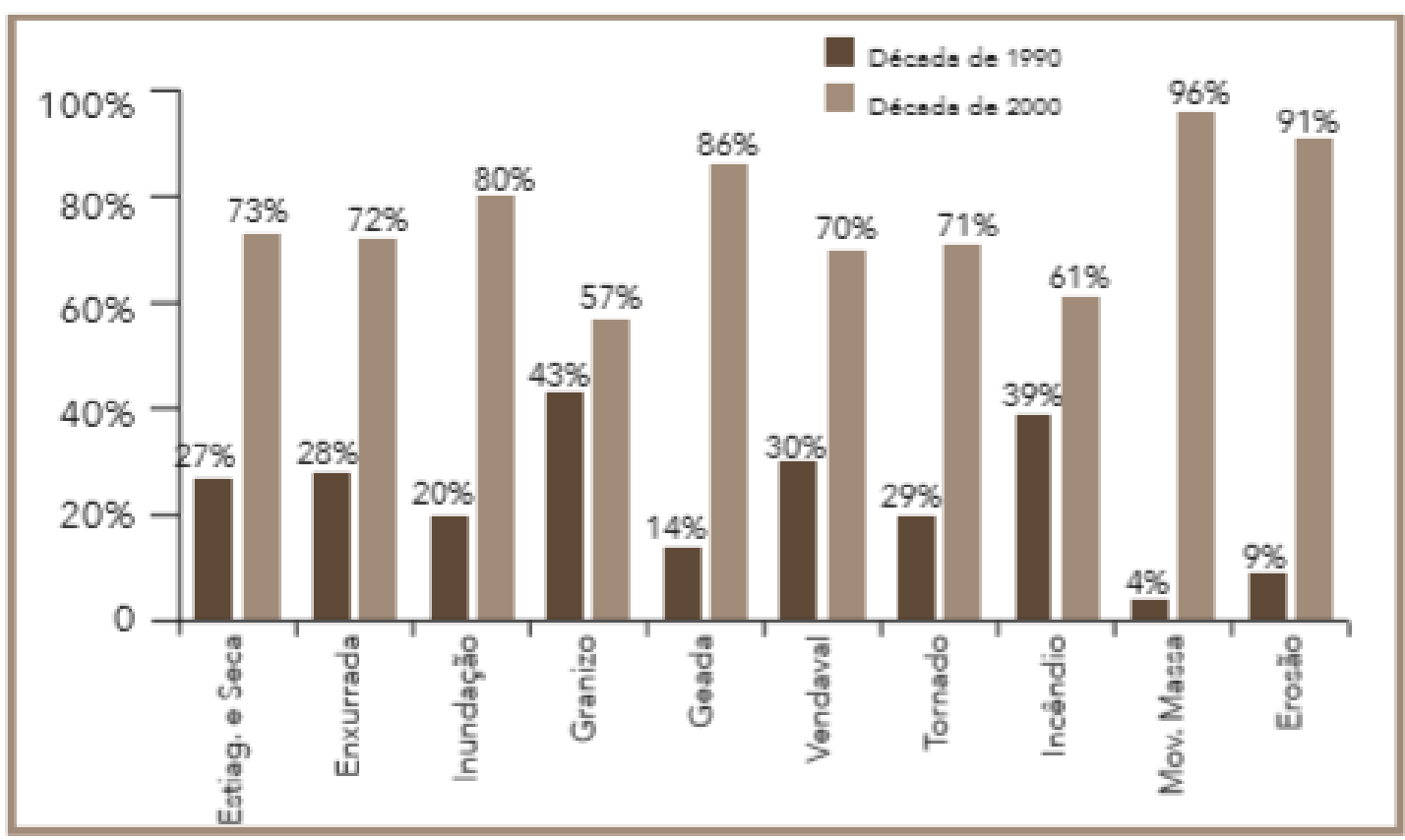

De fato os eventos com maiores índices de recorrências no território brasileiro e cujos impactos são mais severos, seja em termos de perdas materiais e financeiras, quanto em termos de perdas humanas, são aqueles decorrentes de inundações, enxurradas, movimento de massa, que são os deslizamentos de encostas, além das estiagens, secas e vendavais. Neste contexto, o ambiente urbano, por abrigar grande parte da população, quando palco de enchentes e deslizamentos de encostas, constitui-se como o espaço cujas consequências são mais drásticas.

Historicamente, o Brasil $^{1}$ foi visto sob um panorama de imunidade em relação aos desastres naturais, o que como resultado, acabou por deixar hirto o estudo sistematizado e multidisciplinar do fenômeno dos desastres. No entanto, devido ao incremento da intensidade e da periodicidade de tais eventos no contexto nacional, este é um prognóstico que não mais prevalece na sociedade contemporânea, uma vez que até mesmo as empresas de seguro já assinalam uma realidade na qual os desastres sobrevêm como uma constância.

\footnotetext{
1 Natural disasters will likely become more frequent in Brazil and also more costly in terms of human lives and government expenditures, said Fabio Corrias, Swiss Re's head of corporate solutions for Brazil and the rest of the Southern Cone. Brazil has traditionally had a very low exposure to natural disasters, but during the last five years the frequency of events such as heavy rains, floods and avalanches has increased, Corrias told a conference in Sao Paulo hosted by the Swiss reinsurer. The latest such events occurred in January this year in the states of Sao Paulo and Rio de Janeiro, when floods killed more than 800 people and left some 6,000 homeless. Corrias noted that due to lack of insurance and reinsurance, this event cost the public sector US\$460mn in emergency spending. The area most exposed to natural disasters in Brazil is the south east due to high population density, Corrias said (RINDEBRO, 2011, apud FARBER, 2012).
} 
Os deslizamentos de terras são fenômenos que se manifestam na crosta terrestre independente da atuação antropogênica. Ocorrem geralmente por conta do natural enfraquecimento das encostas, diante da ocorrência abundante e prolongada de chuvas que saturam e minimizam a resistência do solo. Em que pese esse fenômeno natural ostentar impactos de grandes dimensões, pode-se dizer que pelas condições geológicas prevalecentes no território nacional, a ocorrência de tais eventos é relativamente excepcional. Todavia, outros fatores contribuem de forma decisiva para o incremento da frequência e intensidade dos deslizamentos de terras, notadamente os modelos não apropriados de ocupação urbana em zonas de média para alta declividade.

As enchentes, por sua vez, são acontecimentos ocasionados por conta de oscilações naturais do sistema pluviométrico. Contudo, tais episódios naturais ocorridos nos cursos d'água são intensificados pela excessiva canalização dos córregos e rios, assim como pela impermeabilização das bacias hidrográficas, o que consequentemente, gera espaços de elevados índices de inundações em regiões que inicialmente poderiam ter uma condição segura.

Embora os desastres associados aos deslizamentos de terras e às enchentes em um primeiro momento estarem ligados a causas essencialmente tidas como naturais, não há que se olvidar que a atuação humana igualmente promove ingerências cujas consequências repercutem em desastres desta ordem. Desse modo, faz-se mais prudente qualificar os desastres como socioambientais, de modo a, por justo, articular o fenômeno às origens naturais e antropogênicas.

De fato, é importante que a temática dos riscos e desastres não seja articulada tão somente pela vertente das ciências naturais. É importante que o qualitativo natural dos desastres, não seja considerado de forma isolada, como seu único qualificador, posto que contribui para a concepção de que o mundo é assim, e nesse sentido não há o que se possa fazer para evitar ou até mesmo minimizar os impactos adversos dos desastres. Outrossim, entender a construção social do risco implica na necessária remodelação da hermenêutica dos desastres, de naturais para socioambientais.

Por conta do processo de urbanização do Brasil, o componente social dos desastres é significativamente relevante. O tradicional desazo na promoção de moradia adequada e digna para a população de todos os estratos sociais, sobretudo para população de baixa renda, aliado ao insuficiente ordenamento territorial que privilegie o interesse social, é um dos fatores que contribuem para a vulnerabilidade das cidades aos desastres.

As camadas populares, ante a impossibilidade de escolha pela moradia formal e legal, sujeitam-se a autoconstrução, seja em propriedades públicas ou privadas, mas cujo valor de mercado é sobremaneira inferior em função das restrições à ocupação legal. Nesse contexto, tem-se a ocupação de morros, de áreas 
cuja declividade é acentuada e de beira dos cursos d'água, de forma a potencializar os riscos de deslizamentos e inundações.

\begin{abstract}
As decisões de ocupação do solo também consistem em fatores de incremento dos riscos e custos decorrentes dos desastres. A ocupação de áreas de risco é um fator determinante para a ocorrência ou agravamento de um evento à condição de desastres. É a partir da ocupação de áreas especialmente vulneráveis que se tem uma intensificação das probabilidades e magnitudes de riscos de inundações, deslizamentos, terremotos, incêndios, entre outros. Este fator de agravamento de risco catastrófico é especialmente relevante no caso brasileiro, uma vez que os desastres ambientais, cada vez mais constantes no país, apresentam relação direta com a ocupação irregular das áreas de preservação permanente - APP (vegetação em topo e encostas de morros, nas margens de rios, lagos e lagoas artificiais etc.). Neste sentido, os deslizamentos ocorridos no vale do rio Itajaí em 2008 e na zona serrana do Rio de Janeiro em 2011 têm ligação importante, porém não exclusiva, com o estado de conservação da vegetação natural nos topos de morros, nas encostas e mesmo nos sopés. Estas áreas atuam como "infraestruturas verdes" de proteção às catástrofes (como veremos a seguir), sendo a sua ocupação irregular um dos principais fatores de ocorrência e potencialização de desastres naturais no Brasil. Tais decisões (no sentido de se viver em localidades de risco) são marcadas não apenas pela vulnerabilidade social de determinadas comunidades, mas também estão delineadas pela ordenação local do solo (medidas não estruturais), sendo estas altamente influenciadas, no contexto brasileiro, pela gestão pública municipal (CARVALHO; DAMACENA, 2013, p. 48 e 49).
\end{abstract}

Portanto, em função das condições brasileiras de urbanização, uma política hábil à prevenção de desastres no ambiente urbano não pode desconsiderar o enfrentamento ao déficit habitacional que seja conjuntamente desenvolvido a partir de ações de minimização dos riscos existentes a níveis toleráveis. Desta feita, os programas habitacionais ostentam relevante função na política de prevenção de desastres urbanos e mitigação de riscos, uma vez que assim têm o condão de enfrentar estruturalmente um dos maiores agentes responsáveis pela existência de zonas de alto risco, qual seja a ausência de alternativas de moradia legal, formal e segura para os estratos populares mais desfavorecidos economicamente.

Neste contexto, as políticas de prevenção de desastres que são fundamentadas tão somente na remoção dos assentamentos informais, sem o devido reassentamento das famílias em local adequado, estão remetidas ao insucesso, uma vez que desconsideram que a crise por moradia é uma das principais fontes causais do risco. De fato, a política habitacional, de forma isolada, não logra êxito no enfrentamento ao desafio da construção de cidades resilientes. Para tanto, faz-se necessário a articulação de medidas estruturais e não estruturais capazes de dar conta da situação de risco já estabelecida nas cidades.

\title{
A incorporação do viés protetivo da gestão de risco na agenda de políticas públicas
}

Tradicionalmente no Brasil a gestão de risco de desastres é marcada substancialmente por um caráter reativo, ou seja, as tomadas de ações públicas se manifestam somente quando já concretizadas perdas humanas e econômicas decorrentes de um desastre. Além disso, em regra, se legisla em matéria de risco de desastres após a incidência de uma catástrofe. 
Contrariando o entendimento de certa forma já arraigado na sociedade brasileira, isto é, de que o país é imunizado e inatingível pelos desastres naturais. Determinados acontecimentos, notadamente aqueles que se sucederam no intervalo de tempo entre os anos de 2008 e 2011, em razão de sua grande magnitude, acabaram por impor a incorporação da temática na agenda de políticas públicas nacionais. Neste lapso temporal, ganharam notoriedade perante a sociedade os episódios ocorridos em Santa Catarina no ano de 2008, em Pernambuco e Alagoas em 2010 e o da região serrana do Rio de Janeiro em janeiro de 2011.

A consciência dessa nova realidade no contexto nacional, na qual os desastres não são mais vistos como eventos excepcionais, vai paulatinamente sendo construída. A Terceira Conferência Mundial Sobre Redução de Risco de Desastres, realizada no Japão em 2015, onde no ensejo foi instituído o Marco de Ação Sendai 2005/2030, foi o primeiro evento de grande porte dessa natureza que contou com a participação do Brasil. No entanto, o envolvimento da sociedade brasileira com a matéria sobreveio na retaguarda de uma série de acontecimentos dramáticos, notadamente o episódio que foi vislumbrado em janeiro 2011 na região serrana do Rio de Janeiro.

Severas inundações ocorreram em Santa Catarina em novembro de 2008, na bacia hidrográfica do Vale do Itajaí. Blumenau e Joinville tiveram um descomunal registro de chuvas, o que foi manifestado como um dos piores desastres da história da região. Inundações, enchentes e deslizamento de encostas afetaram radicalmente a população local, e conforme dados produzidos pelo Banco Mundial no relatório de perdas e danos, salvo os 110 registros de mortes, a eventualidade deixou mais de 80 mil pessoas desalojadas e desabrigadas, 60 Municípios entraram em estado de emergência, e 14 Municípios decretaram situação de calamidade pública.

No tocante ao caso de Alagoas e Pernambuco, a situação ocorrida em junho de 2010 também envolve a incidência de intensas chuvas na bacia dos rios Mundaú, Paraíba e Uma, impactando drasticamente cerca de 94 Municípios dos dois Estados nordestinos. Especificamente em Pernambuco choveu em 24 horas $70 \%$ do volume total de chuvas estimada para o mês. A força da enchente teve o potencial para enternecer cidades inteiras, como foi o que aconteceu nos Municípios de Palmares e Barreiros. “Os números demonstram a magnitude do evento cujo poder destrutivo foi reforçado pelos transbordamentos dos rios e pela saturação do solo" (BANCO MUNDIAL, 2012).

Inobstante a magnitude do referido desastre, é possível concluir que as avarias humanas, em certo sentido, foram minimizadas, na medida em que a soma de 20 mortes foram registradas como sequela do evento. Este diga-se reduzido número de óbitos, quando se considera a violenta grandiosidade do evento é corolário da ação dos sistemas de alerta. Conforme informações do governo do Estado de Pernambuco, às 16 h00 do dia 17 de junho de 2010, o Laboratório de Meteorologia de Pernambuco (LAMEPE), emitiu o alerta 
ao governo do Estado, que duas horas depois transmitiu o alerta às Defesas Civis Municipais, requerendo, portanto, a desocupação das áreas de risco. (BANCO MUNDIAL, 2012).

O fenômeno meteorológico onda de leste que avançou sobre o Estado de Pernambuco, chegou dias depois ao Estado de Alagoas ocasionando impactos negativos econômicos e sociais nos Municípios afetados. De acordo com os dados levantados pelo Banco Mundial foram cerca de 270 mil indivíduos afetados, dentre os quais 44 mil desalojados e mais de 28 mil desabrigados ${ }^{2}$. Além disso, foram registrados a importância de 1.131 pessoas feridas e 36 registros de óbitos.

Os acontecimentos tanto de Pernambuco quanto de Alagoas atingiram uma soma considerável de Municípios de pequeno porte, grande parte com menos de 50.000 habitantes. E nesse sentido, ainda evidenciou que, além do despreparo nas ações de resposta frente à ocorrência de desastres, há uma implacável necessidade de assistência e apoio da esfera estadual e também da federal, a fim de que seja possível proceder à recuperação e reconstrução das comunidades acometidas.

Em janeiro de 2011, entre os dias 11e 12, uma superabundante quantidade de chuvas provocaram inundações e deslizamento de terras impiedosos na região serrana do Estado do Rio de Janeiro. O Banco Mundial destaca que entre as setes cidades impactadas - Areal, Bom Jardim, Nova Friburgo, São José do Vale do Rio Preto, Sumidouro, Petrópolis e Teresópolis - 300 mil pessoas foram atingidas e documentadas 905 mortes, pelo que ficou sinalizado como um dos piores desastres brasileiros dos últimos tempos.

Os três desastres então mencionados, quais sejam: Vale do Itajaí em 2008, Alagoas e Pernambuco em 2010, e o da região serrana do Estado do Rio de Janeiro em 2011, exigiram, de certa forma, uma mudança de conduta por parte do governo federal. Além disso, as três grandes tragédias ora referidas, com destaque para o acontecimento no Estado do Rio de Janeiro em 2011, foram o estopim para as iniciativas de restauração do arranjo do Sistema Nacional de Defesa Civil.

\footnotetext{
Estudos do banco mundial calcularam as perdas e danos dessas catástrofes, por meio da metodologia construída pela CEPAL - Comissão Econômica para América Latina - considerando os impactos diretos e indiretos sobre a infraestrutura, setores sociais, setores produtivos e meio ambiente locais. Somados, os danos e perdas dos desastres de Santa Catarina, Pernambuco e Alagoas, e Rio de Janeiro chegam a R\$15 bilhões (BERTONI, MARINHO, 2013, p. 9).
}

\footnotetext{
${ }^{2}$ A fim sanar eventuais confusões decorrentes da proximidade entre o significado das expressões desabrigados e desalojados, a Defesa Civil construiu um glossário que remete à diferença entre os termos. Assim sendo, consoante o entendimento do governo federal, através do Ministério da Integração Nacional, desabrigado refere-se à pessoa cuja habitação foi afetada por dano ou ameaça de dano e que necessita de abrigo provido pelo Sistema. Ao passo que o termo desalojado é atribuído à pessoa que foi obrigada a abandonar temporária ou definitivamente sua habitação, em função de evacuações preventivas, destruição ou avaria grave, decorrentes do desastre, e que, não necessariamente, carece de abrigo provido pelo sistema. Disponível em: <http://www.In tegracao.gov.br/c/document_library/get_file? uuid=71458606-5f48-462e-8f03-4f61de3cd55f\&gro upld=10157>. Acesso em: 13 out. 2017.
} 
Os recorrentes desastres com aspectos catastróficos em território brasileiro ocasionaram uma resposta política para a gestão de risco de desastres no âmbito nacional, com a aprovação da Lei Federal no 12.608/2012, que instituiu a Política Nacional de Proteção e Defesa Civil, a qual se consagrou como marco legal para a gestão de risco de desastres no contexto brasileiro.

Em 11 de outubro de 2011, nos termos do art. 62 CF/88, foi editada a Medida Provisória 547. A moção inicial contou com a participação conjunta do Ministério da Justiça, Ministério do Meio Ambiente, Ministério da Integração Nacional e Ministério das Cidades. Pela apreciação do texto no qual os Ministérios envolvidos submetem à Presidência da República a exposição de motivos referentes à proposta da Medida Provisória, pode-se constatar que de fato não havia o desígnio de se construir um novo paradigma para o Sistema Nacional de Defesa Civil consubstanciado em uma Política Nacional de Proteção e Defesa Civil. No entanto, percebe-se a preocupação dos referidos Ministérios em estruturar uma abordagem integrada de gestão de risco, com a necessidade de importantes ações no campo da prevenção, articulada nos três níveis de governo.

Ao que a MP 547/2011 estava prestes a perder a validade, em razão do decurso de tempo, houve a sua conversão na Lei 12.608/2012, instituindo, portanto, a Política Nacional de Proteção e Defesa Civil, que se constitui como um novo marco regulatório para a gestão de risco de desastres no Brasil, ordenado, sobretudo, em uma filosofia de proteção e de prevenção. Na realidade, a Lei 12.608/2012 é fruto não apenas da conversão em lei da MP 547/2011, mas também de determinados dispositivos resultantes do Projeto de Lei 2.978/2011, que visava instituir o Estatuto da Proteção Civil, resultado da Comissão Especial da Câmara dos Deputados, destinada a efetuar estudo e apresentar proposta em relação às medidas preventivas e Saneadoras diante de Catástrofes Climáticas.

\section{O gerenciamento de riscos de desastres e o planejamento urbano}

Como já demonstrado, os episódios ocorridos na bacia do Vale do Itajaí em 2008; nos Estados de Pernambuco e Alagoas em 2010; e o da região serrana do Estado do Rio de Janeiro em 2011; todos envolvendo a incidência de severas chuvas, enchentes e deslizamento de encostas, podem ser considerados como irritações sistêmicas, na medida em que impulsionaram uma resposta política, que se concretizou com a aprovação da Lei Federal no 12.608/2012.

O âmago da Política Nacional de Proteção e Defesa Civil (PNPDEC), instituída pela Lei no 12.608/2012, concentra-se nos princípios da proteção e prevenção. Eis a mudança de paradigma, já que altera a orientação dos esforços da intervenção pública em termos de gestão de risco notadamente para o aspecto da prevenção dos desastres, o qual anteriormente era intensivamente direcionado para o momento pós-desastre. 
Inobstante a Lei 12.608/12 remediar o vazio legislativo, na medida em que se constitui em um marco regulatório para os desastres no Brasil, não há que se olvidar que legislações anteriores já tratavam da temática, como é o caso dos Decretos N. ${ }^{\text {os }} 7.257 / 2010,4.217 / 2002$ e 1.080/1994, contudo sem a atenção necessária às medidas preventivas, e de maneira que até então a atuação de todos os agentes envolvidos, bem como da sociedade civil se pautavam em ações essencialmente a posteriori.

No Brasil, até a vigência da PNPDEC, apenas legislou-se em termos de gestão de risco de desastres após a manifestação de uma conjuntura dramática, geralmente chuva ou seca, e com vistas a abreviar o repasse de recursos financeiros destinados primordialmente às ações de resposta. O gerenciamento de riscos no contexto nacional e a própria atuação da defesa civil sempre foi pautada por um caráter mais reativo, sem quaisquer reflexos na seara do planejamento urbano voltada à gestão de riscos ambientais urbanos.

De fato o caráter reativo até o ano de 2010 sempre foi a especificidade maior das políticas públicas de gestão de risco de desastres. Prova disso é a evolução acentuada de recursos públicos destinados à resposta a desastres, já que "em sete anos, entre 2004 e 2010, sofreram aumento de 23 vezes". (BERTONE, MARINHO, 2013). Além disso, a atuação das entidades públicas sempre foi isolada, carecendo de integração e articulação intragovernamental. Nesse sentido, além do relevo à ótica protetiva, outra orientação inerente à gestão de risco de desastres é a de que a PNPDEC deve integrar-se às políticas de ordenamento territorial, desenvolvimento urbano, saúde, meio ambiente, mudanças climáticas, gestão de recursos hídricos, geologia, infraestrutura, educação, ciência e tecnologia e às demais políticas setoriais, tendo em vista a promoção do desenvolvimento sustentável. (art. 3으).

A cidade evidencia as diferentes maneiras pelas quais a sociedade se arranja no território, constituindose na conversão do ambiente natural para o ambiente construído. Contudo, tal modificação processou-se em um ritmo demasiadamente veloz, de modo que a dinâmica dos processos físicos não evolui na mesma proporção, o que contribui em grande medida para a criação e ampliação de riscos, que em não poucas vezes, alcançam a condição de desastres. Nesse contexto, “o palco maior das calamidades naturais tem sido o espaço urbano, que cresce em termos de área ocupada pelas cidades e da proporção de pessoas que a habitam" (NUNES, 2015).

A partir da década de 1950 intensificou-se o processo de urbanização do país, sem a intensificação na mesma toada de políticas públicas de desenvolvimento urbano capazes de promover moradia digna e segura. Sob esta perspectiva, houve uma verdadeira proliferação de assentamentos precários nas cidades, que se inseriram e se expandiram em espaços de elevada declividade e às margens de rios e córregos, resultando, desse modo, em parcelas urbanas extremamente vulneráveis a desastres ambientais urbanos. 
Não há que se olvidar que bairros legalmente instaurados igualmente estão sujeitos aos desastres mais corriqueiramente manifestados nos ambientes construídos, como enxurradas, deslizamento de terras e enchentes. Isso porque ainda é incipiente a incorporação da agenda ambiental pelos gestores das cidades, assim como o entendimento do comportamento do meio físico e natural não foi, ao menos de modo satisfatório, incorporado às mais variadas legislações de cunho urbanístico, sejam planos diretores ou legislações de uso e ocupação do solo. De igual modo, não é rara a aprovação de loteamentos em espaços cujas condições naturais e geológicas não orientam à utilização para o uso permanente.

Ademais a vulnerabilidade decorrente de todo este processo desordenado de urbanização ainda é potencializada pelas mudanças climáticas. "Mudança climática refere-se tecnicamente à análise de alterações nas médias de clima, observando especialmente dados de temperatura e precipitação". (KLUG, 2018). A esse respeito convém ressaltar a pesquisa realizada no ano de 2011 pelo Painel Intergovernamental de Mudanças Climáticas - IPCC- intitulada Managing the risks of extreme events and disasters to advance climate change adaptation: Special report $f$ the intergovernmental panel on climate change ${ }^{3}$. Trata-se de uma robusta pesquisa que aborda em um contexto hodierno, as novas dimensões dos riscos de desastres sob uma perspectiva mundial. Neste ínterim propõe a seguinte reflexão acerca das complexas interações entre eventos climáticos, exposição e vulnerabilidade, a saber:

\begin{abstract}
There exist complex interactions between different climatic and nonclimatic hazards, exposure, and vulnerability that have the potential of triggering complex, scale-dependent impacts. Anthropogenic changes in atmospheric systems are influencing changes in many climatic variables and the corresponding physical impacts. However, the impacts that climatic extremes have on humans and ecosystems (including those altered by humans) depend also on several other nonclimatic factors. [...] Changes in socioeconomic status are a key component of exposure; in particular, population growth is a major driver behind changing exposure and vulnerability (Downton et al., 2005; Barredo, 2009). In many regions, people have been encroaching into flood-prone areas where effective flood protection is not assured, due to human pressure and lack of more suitable and available land (McGranahan et al., 2007; Douglas et al., 2008). Urbanization, often driven by rural poverty, drives such migration (Douglas et al., 2008). In these areas, both population and wealth are accumulating, thereby increasing the flood damage potential. In many developed countries, population and wealth accumulation also occur in hazard-prone areas for reasons of lifestyle and/or lower cost (e.g., Radeloff et al., 2005). Here, a tension between climate change adaptation and development is seen; living in these areas withoutappropriate adaptation may be maladaptive from a climate change perspective, but this may be a risk people are willing to take, or a risk over which they have limited choice, considering their economic circumstances (Wisner et al., 2004). Furthermore, there is often a deficient risk perception present, stemming from an unjustified faith in the level of safety provided by flood protection systems and dikes in particular (Grothmann and Patt, 2005) (e.g., 2005 Hurricane Katrina in New Orleans) (IPCC, 2011, p. 238). ${ }^{4}$
\end{abstract}

\footnotetext{
${ }^{3}$ Tradução Livre: Gerenciando os riscos de eventos extremos e desastres para avançar na adaptação às mudanças climáticas: relatório especial do painel intergovernamental sobre mudanças climáticas.

${ }^{4}$ Tradução livre: Existem interações complexas entre diferentes riscos climáticos e não climáticas exposição e vulnerabilidade que têm o potencial de desencadear impactos complexos e dependentes da escala. As mudanças antropogênicas nos sistemas atmosféricos estão influenciando as mudanças em muitas variáveis climáticas e os impactos físicos correspondentes. No entanto, os impactos que os extremos climáticos têm em seres humanos e ecossistemas (incluindo aqueles alterados por humanos) dependem também de vários outros fatores não-climáticos. [...]As mudanças no status socioeconômico são um componente chave da exposição; em particular, o crescimento populacional é um dos principais impulsionadores da mudança de exposição e vulnerabilidade (Downton et al., 2005; Barredo, 2009). Em muitas regiões, as pessoas têm vindo a invadir as áreas propensas a inundações onde a proteção eficaz contra inundações não é assegurada, devido à pressão humana e à falta de terras mais adequadas e disponíveis (McGranahan et al., 2007; Douglas et al., 2008). A urbanização, muitas vezes impulsionada pela pobreza rural, impulsiona essa migração (Douglas et al., 2008). Nessas áreas, tanto a população como a riqueza se acumulam, aumentando assim o potencial de danos causados pelas inundações.
} 
Diante da complexidade peculiar associada à manifestação dos desastres no ambiente construído, o eficaz gerenciamento de riscos ambientais urbanos deve levar em conta as mais diversificadas políticas setoriais. Todavia, a agenda urbana especificamente, demanda maior proeminência. Não é sem motivo que grande parte dos objetivos da PNPDEC guarda estreita relação com a questão urbana. Assim, destacam-se os incisos IV, VI, X, XI e XII do art. 4ํㅡ, os quais, respectivamente, mencionam enquanto objetivos da lei: incorporar a redução de risco de desastres e as ações de proteção e defesa civil entre os elementos da gestão territorial e do planejamento de políticas setoriais; estimular o desenvolvimento de cidades resilientes e os processos sustentáveis de urbanização; estimular o ordenamento da ocupação do solo urbano e rural, tendo em vista sua conservação e a proteção da vegetação nativa, dos recursos hídricos e da vida humana; combater a ocupação das áreas ambientalmente vulneráveis e de risco e promover a realocação da população residente nessas áreas; estimular iniciativas que resultem na destinação de moradia em local seguro.

Nesta senda, a Nova Agenda Urbana, a qual foi aprovada no Equador em 2016, no bojo da Conferência Habitat III, apresentou para os próximos vinte anos, os compromissos que devem direcionar a atuação dos governos a fim de alcançar o desenvolvimento urbano resiliente e ambientalmente sustentável. Desse modo, a nova agenda urbana afirma que é condição para a construção de cidades justas e socialmente inclusivas, a redução do nível de vulnerabilidade das cidades, intrinsecamente associado à diminuição de assentamentos informais, sobretudo os situados em zonas consideradas de risco.

\begin{abstract}
Consideradas as questões demográficas e os esforços para mitigação e adaptação às mudanças do clima e definidas as premissas para o uso dos recursos e dos ecossistemas, a forma como as cidades são planejadas, financiadas, desenvolvidas, construídas, governadas e administradas tem impacto direto sobre questões de sustentabilidade e resiliência muito além de seus limites urbanos. 0 policy paper 8 (Urban ecology and resilience) e os issue papers 15 (Urban resilience), 16 (Urban ecosystems and resource management) e 17 (Cities and climate change and disaster risk management) tratam dos compromissos e das ações que precisam ser adotados pelos governos para que haja incorporação no processo de planejamento dessas questões. $O$ texto final do policy paper 8 reforçou os principais temas da agenda urbanoambiental e apresentou a vinculação da Nova Agenda Urbana com os Objetivos de Desenvolvimento Sustentável (ODS) da Organização das Nações Unidas (ONU), demonstrando que sete objetivos ou vinte metas, mais especificamente, se relacionam com ela. Evidentemente, o ODS 11 tornar as cidades inclusivas, seguras, resilientes e sustentáveis - é o que traduz melhor essa integração. (KLUG, 2018, p. 84).
\end{abstract}

Com efeito, o planejamento urbano ambiental é importante mecanismo hábil a fomentar o equilíbrio entre o desenvolvimento econômico e a sustentabilidade ambiental, bem como na construção de cidades resilientes. Sob este enfoque, o ente municipal é o grande protagonista, já que pelo desenho constitucional é

Em muitos países desenvolvidos, a acumulação de população e riqueza também ocorre em áreas propensas a riscos por razões de estilo de vida e / ou menor custo (por exemplo, Radeloff et al., 2005). Aqui, vê-se uma tensão entre a adaptação e o desenvolvimento das mudanças climáticas; viver nessas áreas sem uma adaptação apropriada pode ser inadaptado a uma perspectiva de mudança climática, mas isso pode ser um risco que as pessoas estão dispostas a tomar, ou um risco sobre o qual eles têm escolha limitada, considerando suas circunstâncias econômicas (Wisner et al., 2004). Além disso, muitas vezes existe um déficit de percepção de risco presente, decorrente de uma fé injustificada no nível de segurança provido por sistemas de proteção contra inundações e diques em particular (Grothmann e Patt, 2005) (por exemplo, o furacão Katrina 2005 em Nova Orleans). 
o ente competente a promover o adequado ordenamento territorial, mediante planejamento e controle do uso, do parcelamento, e da ocupação do solo urbano.

Consoante disposição constitucional a política de desenvolvimento urbano, cuja competência para a devida execução é atribuída ao Poder Público municipal, tem como principal objetivo o pleno desenvolvimento das funções socioambientais da cidade e a garantia do bem-estar de todos seus habitantes. Nesta esteira, o plano diretor é extremamente importante, pois é considerado o instrumento básico da política de desenvolvimento e expansão urbana.

O manejo da política de desenvolvimento urbano pelo ente público municipal deve se dar nos termos das diretrizes gerais dispostas na Lei Federal no 10.257/2011, o Estatuto da Cidade. A referida legislação de natureza urbanística dispõe em seus mandamentos de orientações para a execução da política urbana, trazendo o conteúdo mínimo que deve ser observado pelos gestores municipais para a elaboração dos planos diretores. Além disso, dispõe de uma série de importantes instrumentos jus-urbanísticos, que quando devidamente manejados contribuem para o cumprimento das funções socioambientais da cidade e da propriedade urbana como forma de garantir o direito a cidades sustentáveis.

Considerando que o crescimento urbano não ordenado potencializa a proliferação de áreas de risco ambiental em zonas urbanas a harmonização entre o gerenciamento de risco de desastres e o planejamento urbano é medida que se impõe. Desta feita, a Política Nacional de Proteção e Defesa Civil, instituída pela Lei no 12.608/12, além de se consagrar como uma disaster Law altera de modo sistêmico, uma série de outros marcos regulatórios, dentre os quais se destaca o Estatuto da Cidade.

Nesse sentido a Lei no 12.608/12, insere uma nova diretriz que deve orientar os instrumentos de política urbana constantes no Estatuto da Cidade, que é a de que a ordenação e controle do uso do solo deve evitar a exposição da população a riscos de desastres. Além disso, insere a obrigatoriedade do plano diretor para as cidades incluídas no cadastro nacional de municípios com áreas suscetíveis à ocorrência de deslizamentos de grande impacto, inundações bruscas ou processos geológicos ou hidrológicos correlatos.

Contudo, passados mais de sete anos da aprovação da Lei no 12.608/2012, até o presente momento, o referido cadastro cuja competência para elaboração é do Governo Federal, não foi implementado. Aliás, é disposto no texto legal que as definições técnicas para aplicação desta Lei serão estabelecidas em ato do Poder Executivo Federal. Em que pese o déficit regulamentar, o que se dispõe até então é de um cadastro de municípios prioritários, no qual estão incluídos 821 municípios. Esses 821 municípios considerados prioritários “representam 94\% das mortes e 88\% das pessoas afetadas. Desses, existe priorização de 286, sem hierarquia, correspondentes a $89 \%$ das mortes e $55 \%$ do total de pessoas desalojadas ou desabrigadas". (BERTONE, MARINHO, 2013). 
[...] Uma atenta análise interpretativa ao conteúdo das orientações urbanísticas trazidas pela Lei no $12.608 / 12$ e que alteram, principalmente, as Leis no $12.340 / 10$ e 10.257/01, demonstra que tais restrições atingem aqueles municípios que aderiram ou foram incluídos no chamado cadastro de municípios com áreas suscetíveis a ocorrência de deslizamentos de grande impacto, inundações bruscas ou processos geológicos ou hidrológicos correlatos.

Contudo, esse sistema normativo encontra-se em verdadeiro risco quanto à sua plena eficácia e normatividade, uma vez que o referido cadastro ainda não foi regulamentado pelo governo federal, havendo assim a impossibilidade de aplicação plena das restrições urbanísticas previstas na sistemática trazida pela Política Nacional de Proteção e Defesa Civil (Lei no 12.608/12).

Uma vez mais se faz necessário a análise aprofundada, neste momento, sobre o déficit regulamentar. O texto normativo é cristalino ao determinar que "o governo federal instituirá cadastro..., conforme regulamento. Cadastro este que deve ser instituído por meio de Decreto, a partir do poder regulamentar atribuído pela Constituição Federal ao Poder Executivo, nos termos do art. 84, IV.

Para casos como este, a doutrina jurídica brasileira tem entendido que em casos de leis que tenham previsão de serem regulamentadas para sua aplicação não são exequíveis até que o ato regulamentar seja expedido. [...] (CARVALHO, 2017, p. 363 e 364).

Mas além de inserir a obrigatoriedade da elaboração do Plano Diretor para os municípios suscetíveis à ocorrência de deslizamentos de grande impacto, inundações bruscas ou processos geológicos e hidrológicos correlatos, 0 art. 26 da PNPDEC insere $o$ art. 42-A na Lei no 10.257/01, que em complemento ao art. 42, dispõe acerca do conteúdo essencial dos planos diretores para os municípios tidos como vulneráveis aos riscos urbanos.

\footnotetext{
Art. 26. A Lei no 10.257, de 10 de julho de 2001, passa a vigorar acrescida dos seguintes arts. 42-A e 42B:

“ Art. 42-A. Além do conteúdo previsto no art. 42, o plano diretor dos Municípios incluídos no cadastro nacional de municípios com áreas suscetíveis à ocorrência de deslizamentos de grande impacto, inundações bruscas ou processos geológicos ou hidrológicos correlatos deverá conter:

I - parâmetros de parcelamento, uso e ocupação do solo, de modo a promover a diversidade de usos e a contribuir para a geração de emprego e renda;

II - mapeamento contendo as áreas suscetíveis à ocorrência de deslizamentos de grande impacto, inundações bruscas ou processos geológicos ou hidrológicos correlatos;

III - planejamento de ações de intervenção preventiva e realocação de população de áreas de risco de desastre;

IV - medidas de drenagem urbana necessárias à prevenção e à mitigação de impactos de desastres; e V - diretrizes para a regularização fundiária de assentamentos urbanos irregulares, se houver, observadas a Lei no 11.977, de 7 de julho de 2009, e demais normas federais e estaduais pertinentes, e previsão de áreas para habitação de interesse social por meio da demarcação de zonas especiais de interesse social e de outros instrumentos de política urbana, onde o uso habitacional for permitido.

$\S 1$ ㅇ A identificação e o mapeamento de áreas de risco levarão em conta as cartas geotécnicas.

§ 2ㅇ O conteúdo do plano diretor deverá ser compatível com as disposições insertas nos planos de recursos hídricos, formulados consoante a Lei no 9.433, de 8 de janeiro de 1997.

$\S 3$ 응 Os Municípios adequarão o plano diretor às disposições deste artigo, por ocasião de sua revisão, observados os prazos legais.

$\S 4$ o Os Municípios enquadrados no inciso VI do art. 41 desta Lei e que não tenham plano diretor aprovado terão o prazo de 5 (cinco) anos para o seu encaminhamento para aprovação pela Câmara Municipal” (BRASIL, 2012).
}

Outro importante instrumento de política urbana são as cartas geotécnicas de aptidão à urbanização. Dispõe o art. 3ํ-A da Lei no 12.340 que os municípios inseridos no cadastro de suscetibilidade a riscos ambientais urbanos deverão elaborar carta geotécnica de aptidão à urbanização, estabelecendo diretrizes urbanísticas voltadas para a segurança dos novos parcelamentos do solo e para o aproveitamento de agregados para a construção civil. 
Enquanto importante instrumento de planejamento para zonas vulneráveis a desastres ambientais urbanos, a carta geotécnica determina a aptidão de terrenos à urbanização, posto que leva em conta a probabilidade de ocorrência de desastres socioambientais. Dessa forma, os municípios podem contar com um importante subsídio que auxiliará no estabelecimento de diretrizes para expansão urbana, de modo a evitar que se incluam no período urbano de um determinado município zonas mais propensas à ocorrência de desastres.

A elaboração do instrumento em escala devida que permita maior detalhamento das especificidades locais auxilia na definição de diretrizes para a aprovação de novos parcelamentos do solo por parte da municipalidade. Tal medida, consequentemente, certifica que os novos bairros sejam projetados de maneira a minimizar os riscos e as vulnerabilidades que por ventura possam se converter em desastres. Com efeito, ao que tudo indica as cartas geotécnicas até então não deslancharam.

\section{CONSIDERAÇÕES FINAIS}

É relativamente recente a incursão dos temas associados à gestão de risco de desastres enquanto objeto de estudo no campo das ciências sociais, assim como é novel o entendimento de sua necessária articulação às mais variadas políticas setoriais, notadamente em setores nos quais se evidenciam as tomadas de decisões acerca do território urbano. Os esforços nesse sentido foram consolidados apenas no ano de 2012, com a aprovação da Lei Federal no 12.608, que indica a necessidade de articulação entre o gerenciamento de risco de desastres às mais variadas políticas setoriais, dentre as quais se destacam as políticas de ordenamento territorial, desenvolvimento urbano, saúde, meio ambiente, mudanças climáticas, gestão de recursos hídricos, geologia, infraestrutura, educação, ciência e tecnologia.

A Política Nacional de Proteção e Defesa Civil, instituída pela legislação ora mencionada, representa uma mudança de paradigma no gerenciamento de risco de desastres e reforça sua fundamental interface no âmbito da política urbana. Nesse sentido ratifica a alteração da orientação dos esforços da intervenção pública em termos de gestão de risco notadamente para o aspecto da prevenção dos desastres, o qual anteriormente era intensivamente direcionado para o momento pós-desastre.

Além disso, constata-se que a Lei no 12.608 promove alterações sistêmicas em diversas outras legislações, pelo que em termos de planejamento urbano, merece destaque as modificações promovidas na Lei no 10.257/2001, o Estatuto da Cidade. Nesta senda, uma nova diretriz passou a balizar a política urbana nacional, que é a de que a ordenação e o controle do uso do solo deve evitar a exposição da população aos riscos de desastres. 
A política urbana no Brasil, em certo sentido, negligenciou a questão dos riscos ambientais urbanos, prova disso são as regulares ocorrências nos últimos anos de enchentes, inundações, enxurradas e deslizamentos de terras, que, ao que tudo indica, tendem a ser algo frequente no território brasileiro. Todavia, a conformação dos instrumentos de política urbana já existentes ao ideário da proteção e prevenção de desastres, aliado ao correto manejo daqueles instrumentos de política urbana específicos para o gerenciamento de risco de desastres, como as cartas geotécnicas de aptidão a urbanização, são capazes de reduzir as vulnerabilidades, mitigar os impactos dos desastres e projetar cidades mais resilientes.

Com efeito, houve um salto entre 2011 e 2012 no que tange ao gerenciamento de risco de desastres associado à política urbana, mas muitas iniciativas importantes não tiveram continuidade. O governo federal lançou em agosto de 2012 o Plano Nacional de Gestão de Risco e Resposta a Desastres Naturais, o qual contava com a promessa de $\mathrm{R} \$ 15,6$ bilhões a serem investidos em ações distribuídas em quatro eixos principais, quais sejam: obras de prevenção; resposta, mapeamento de áreas de risco; e monitoramento e alertas. Contudo, apenas metade do prometido, foi efetivamente gasto.

$\mathrm{Na}$ esteira dos cortes orçamentários e promessas não cumpridas, cabe ressaltar a dificuldade enfrentada na manutenção dos centros federais criados para operar no contexto da gestão de risco, os quais igualmente tiveram redução de equipes ou de verbas. É o caso do Cemaden (Centro Nacional de Monitoramento e Alertas de Desastres Naturais), concebido originalmente para ter 180 funcionários, conta hoje com apenas 103. Além disso, o orçamento do centro de monitoramento foi reduzido em torno de $85 \%$ entre 2013 e 2017. Cabe ressaltar ainda que o Cemaden tem atualmente equipamentos parados que custaram quase $\mathrm{R} \$ 14$ milhões, o que de fato prejudica a continuidade da operação da rede de observação.

Não se pode negar que a Lei no $12.608 / 2012$ tem a sua importância, pois remodela todo o Sistema Nacional de Defesa Civil. Desse modo, apresenta especial ênfase para a ruptura das tradicionais condutas emergenciais para tomadas de decisão de caráter protetivo e preventivo. Com efeito, alguns pontos ainda carecem de maior atenção para que de fato possam ser concretizados, além disso, a regulamentação da PNPDEC em vários pontos ainda é incipiente. De todo modo sempre é válido reiterar que a lei por si só não logra cumprir com a natureza transformadora a que se propõe se não acompanhada de políticas públicas e de incentivos financeiros que lhe auxiliem no cumprimento das diretrizes, metas e objetivos.

\section{REFERÊNCIAS}


ALMEIDA, Paula Emília Gomes de. A política nacional de proteção e defesa civil: os desastres como problema político. Disponível em: <https://www.ufrgs.br/sicp/wp-content/uploads/2015/09/ALMEIDA-Paula-Em\%C3\%ADlia-G.-A-Pol\%C3\%ADtica-N acional-deProte\%C3\%A7\%C3\%A3o-e-Defesa-Civil-desastres-como-um-problema-po I\%C3\% ADtico.pdf>. Acesso em: 20 nov. 2016.

ALVES, Henrique Rosmaninho; RIBEIRO, José Cláudio Junqueira. A política nacional de proteção e defesa civil e a busca pela sustentabilidade nas áreas vulneráveis dos centros urbanos. Disponível em:<https://online.unisc.br/seer/index.php/direito /article/view/5438>. Acesso em: 10 out. 2016.

BECK, Ulrich. Sociedade de Risco: Rumo a uma outra modernidade. 2.ed. São Paulo: Editora 34, 2013.

BECK, Ulrich. La Sociedad del Riesgo Global. Madrid: Siglo Ventiuno de España Editores, 2002.

BERTONE, Pedro; MARINHO, Clarice. Gestão de Risco e Resposta a Desastres Naturais: A Visão do Planejamento. Disponível em: <http://repositorio.fjp.mg.gov.br/consad/handle /123456789/966 >. Acesso em: 26 set. 2017.

BRASIL. Lei no 12.608, de 10 de abril de 2012. Institui a Política Nacional de Proteção e Defesa Civil- PNPDEC; dispõe sobre o Sistema Nacional de Proteção e Defesa Civil- SINPDEC e o Conselho Nacional de Proteção e Defesa Civil- CONPDEC; autoriza a criação de sistema de informações e monitoramento de desastres; altera as leis nos 12.340 de 10 de dezembro de 2010, 10.257 de 10 de julho de 2001, 6.766 de 19 de dezembro de 1979, 8.239, de 4 de outubro de 1991, e 9.394 de 20 de dezembro de 1996, e dá outras providências. Disponível em: <http://www.planalto.gov.br/ccivil_03/_Ato2011-2014/2012/ Lei/L12608 .htm >. Acesso em 22 jul. 2016.

BRASIL. Lei 10.257, de 10 de Julho de 2001. Regulamenta os artigos 182 e 183 da Constituição Federal, estabelece diretrizes gerais da política urbana e dá outras providências. Disponível em: <http://www.planalto.gov.br/ccivil_03/leis/LEIS_2001/L10257. htm>. Acesso em 22 jul.2016.

BRASIL. Ministério do Meio Ambiente. Secretaria de Biodiversidade e Florestas. Relatório de inspeção da área atingida pela tragédia das chuvas na Região Serrana do Rio de Janeiro. Brasília: MMA, 2011.

CÂMARA DOS DEPUTADOS. Comissão Especial Medidas Preventivas e Saneadoras de Catástrofes Climáticas. Disponível em: < http://www2.camara.leg.br/atividade-legislativa/comissoes/comissoes-temporarias/especiais/54a-legislatura/medidas-preventivasdiante-de-catastrofes/arquivos/relatorio-do-dep.-glauber-braga >. Acesso em: 20 set. 2017.

CALDERON RAMIREZ, Daniel Ricardo; FREY, Klaus. El ordenamiento territorial para la gestión del riesgo de desastres en Colombia. Disponível em: < https://revistas.urosario.edu.co/index.php/territorios/article/view/4795>. Acesso em 18 set. 2017.

CARVALHO, Délton Winter de. As mudanças climáticas e a formação do Direito dos Desastres. Disponível em: <http://siaiap32.univali.br/seer/index.php/nej/article/view/ 5130/2690>. Acesso em: 5 jan. 2017.

CARVALHO, Délton Winter de. Desastres Ambientais e sua Regulamentação Jurídica: Deveres de Prevenção, Resposta e Compensação Ambiental. São Paulo: Revista dos Tribunais, 2015.

CARVALHO, Délton Winter de. As Mudanças Climáticas e a Formação do Direito dos Desastres. Disponível em: < siaiap32.univali.br/seer/index.php/nej/article/download/5130/2690>. Acesso em: 05 jul. 2017.

CARVALHO, Délton Winter de; DAMACENA, Fernanda Dalla Libera. Direito dos Desastres. Porto Alegre: Livraria do Advogado, 2013.

CENTRE FOR RESEARCH ON THE EPIDEMIOLOGY OF DISASTERS (CRED). Annual Disaster Statistical Review 2016: The numbers and trends. Disponível em:< http://emdat.be/sites/default/files/adsr_2016.pdf>. Acesso em: 21 nov. 2017.

DAMACENA, Fernanda Dalla Libera. A Formação Sistêmica de um Direito dos Desastres. 2012. 152 f. Dissertação (Mestrado em Direito) - Universidade do Vale do Rio dos Sinos, São Leopoldo, 2012.

DYNES, Russell R. The dialogue between Voltaire and Rousseau on the Lisbon Earthquake: The Emergence of a Social Science View. Disponível em: < http://www.ijmed.org/articles/166/download/ >. Acesso em: 09 Nov. 2017.

EM-DAT. The international Disaster Database. Centre for Research on the Epidemiology of Disaster- CRED. Disponível em: < http://www.emdat.be/>. Acesso em 17 dez. 2016.

ESTARQUE, Marina. Natureza do Desastre- Política de prevenção de desastres definha no país. Disponível em: < https://cetesb.sp.gov.br/proclima/2018/03/02/natureza-do-desastre-politica-de-prevencao-de-desastres-naturais-definha-nopais/>. Acesso em: 19 ago. 2019.

FARBER, Daniel. Disaster Law and emerging issues in Brazil. Revista de Estudos Constitucionais, Hermenêutica e Teoria do Direito(RECHTD), 4(1): 2-15 janeiro-junho, 2012.

FARBER, Daniel. Introduction: The role of the lawyers in a disaster-prone world. Disponivel em:<http://scholarship.law.berkeley.edu/cgi/viewcontent.cgi?article=1751\&context=facpubs. Acesso em 26 jan. 2017.

FARBER, Daniel et. al. Disaster Law and Policy. Aspen Publishers, 2010.

FARBER, Daniel; CARVALHO, Délton Winter de. (Orgs.). Estudos Aprofundados em Direito dos Desastres: Interfaces Comparadas. Curitiba: Editora Prismas, 2017. 
GALVÃo, Thiago; CARVALHO, Celso Santos. Gestão de Risco e Resposta a Desastres Naturais: A atuação do Ministério das Cidades. Disponível em: < http://consadnacional.org.br/wp-content/uploads/2013/05/071-GEST\%C3\%830-DE-RISCOS -E-RESPOSTA-ADESASTRES-NATURAIS-A-ATUA\%C3\%87\%C3\%830-DO-MINIST\% C3 \%89RIO-DAS-CIDADES.pdf >. Acesso em: 20 set. 2017.

GANEM, Roseli Senna. Gestão de Desastres no Brasil. Disponível em: < http://bd.camara.gov.br/bd/bitstream/handle/bdcamara/10496/gestao desastres ganem.pdf?sequence=1 >. Acesso em: 20 set. 2017.

FILHO, Osmar Coelho; JUNIOR, Nilo Luiz Saccaro.Cidades Resilientes e o Ambiente Natural: Ecologia Urbana, Adaptação e Gestão de Riscos. In: COSTA, Marco Aurélio (Org.). Estatuto da Cidade e a Habitat III: um balanço de quinze anos da política urbana no Brasil e a Nova Agenda Urbana. Brasília: Ipea, 2016.

FREIRE, Ana Flávia Rodrigues. A Política Nacional de Proteção e Defesa Civil e as ações do Governo Federal na gestão de risco de desastres. 2014. 137f. Dissertação (Escola Nacional de Saúde Pública Sergio Arouca) - Fundação Oswaldo Cruz, Rio de Janeiro 2014.

FREITAS, Christiana Galvão Ferreira de. Perspectivas e Desafios à Gestão de Risco de Desastres: Uma análise sobre a Configuração do Direito de Desastres no Mundo e no Brasil. 2014. 285 f. Tese de Doutorado (Faculdade de Direito) - Universidade de Brasília, Brasília, 2014.

GIDDENS, Anthony. A política da mudança climática. Rio de Janeiro: Zahar, 2010.

GIDDENS, Anthony. As consequências da modernidade. São Paulo: Unesp, 1991.

INTERNATIONAL FEDERATION OF RED CROSS AND RED CRESCENT SOCIETIES. Law and legal issues in international disaster response: a desk study. Disponível em: <http://www.ifrc.org/PageFiles/125639/113600-idrl-deskstudy-en.pdf >. Acesso em: 15 nov. 2017.

INTERNATIONAL FEDERATION OF RED CROSS AND RED CRESCENT SOCIETIES. International Disaster Response Law. A Preliminary Overview and Analysis of Existing Treaty Law. Disponível em: <https://www.icrc.org/eng/assets/files/other/idrl _report_final_ang.pdf >. Acesso em: 15 nov. 2017.

IPCC. Managing the risks of extreme events and disaster to advance climate change adaptation: special report of the intergovernmental panel on climate change. Disponível em: <https://www.ipcc.ch/pdf/special-reports/srex/SREX_Full_Report.pdf $>$. Acesso em 11 jul. 2017.

KINGDON, John Wells. Agendas, alternativas and public policies. 2. ed. Ann Arbor: University of Michigan, 2003.

KLEIN, Naomi. A doutrina do choque: A ascensão do capitalismo de desastre. Rio de Janeiro: Nova Fronteira, 2007.

KLUG, Letícia. Resiliência e Ecologia Urbana. Disponível em: <

http://repositorio.ipea.gov.br/bitstream/11058/8624/1/Resili\%C3\%AAncia.pdf>. Acesso em: 15 ago. 2019.

KLUG, Letícia; MARENGO, José; LUEDEMANN, Gustavo. Mudanças Climáticas e os Desafios Brasileiros Para Implementação da Nova Agenda Urbana. In: COSTA, Marco Aurélio (Org.). Estatuto da Cidade e a Habitat III: um balanço de quinze anos da política urbana no Brasil e a Nova Agenda Urbana. Brasília: Ipea, 2016.

LAVRATTI, Paula; PRESTES, Vanêsca Buzelato. Direito e Mudanças Climáticas: Inovações Legislativas em Matéria de Mudanças Climáticas. São Paulo: Instituto o Direito por um Planeta Verde, 2010.

LEFF, Enrique. Racionalidad Ambiental: La reapropriación social de la naturaleza. Buenos Aires: Siglo Veinteuno Editores, 2004.

LIEBER, Renato Rocha; LIEBER, Nicolina Silvano Romano. O Conceito de Risco. Janus reinventado. In: MINAYO, Maria Cecília de Souza; MIRANDA, Ary Carvalho (Orgs.) Saúde e Ambiente Sustentável: Estreitando nós. Rio de Janeiro: Editora Fiocruz, 2002.

MACHADO, Silvana Berenice Bazzan; ATZ, Ana Paula. Os desastres ambientais e a gestão de risco de acordo com a lei da política nacional de proteçãoe defesa civil. In: HUPFER, Haide Maria; WEYERMULLER, André Rafael; CUNHA, Daniel Sica da. (Orgs.) Direito 10: Desafios à Efetivação do Direito. Nova Hamburgo: Feevale, 2017.

MASKREY, Andrew (comp.). Los desastres no son naturales. Disponível em: <

http://www.oei.es/historico/decada/portadas/losdesastres.htm>. Acesso em:13 set. 2017.

MINISTÉRIO PÚBLICO DE SÃO PAULO. Temas de Direito Urbanístico 6: Áreas de Risco. São Paulo: Imprensa Oficial, 2012.

MONTEIRO, Vera Lucia. A situação atual de implementação da política nacional de proteção e defesa civil no Estado de São Paulo. Disponível em: <http://www.revistas.udesc.br/index.php/percursos/article/view/1984724618362017194 >. Acesso em: 08 nov. 2017.

MOREIRA, Renata Maria Pinto. Balanço Crítico das Teorias da Sociedade de Risco: rumo a abordagens concretas de falhas urbanas. Disponível em:<

http://anpur.org.br/xviienanpur/principal/publicacoes/XVII.ENANPUR_Anais/ST_Sessoes_Tematicas/ST\%204/ST\%204.5/ST\%204.502.pdf>. Acesso em 13 de jun. 2017.

MOTTA, Ronaldo Seroa da. et. al. Mudança Climática no Brasil: aspectos econômicos, sociais e regulatórios. Brasília, IPEA, 2011. 
NETO, Nicolau Cardoso; SHERER, Kátia Ragnini. Vulnerabilidade e Resiliência: O desastre natural ocorrido no Vale do Itajaí em 2008 como irritação sistêmica para a criação da Política Nacional de Proteção e Defesa Civil- Lei 12.608/2012. Disponívelem: < www.publicadireito.com.br/artigos/?cod=1766fff4851ac9c1>. Acesso em: 21 fev. 2017.

NUNES, Lucí Hidalgo. Urbanização e desastres naturais: abrangência América do Sul. São Paulo: Oficina de textos, 2015.

OJIMA, Ricardo. A vulnerabilidade socioambiental como conceito interdisciplinar: avanços e potencialidades para potencialidades para pensar mudanças ambientais. Disponível em: <https://periodicos.ufrn.br/cronos/article/view/5627>. Disponível em: 03 dez. 2016.

ONU. Painel Intergovernamental de Mudanças Climáticas- IPCC. Disponível em:< http://www.ipcc.ch/>. Acesso em: 15 mar. 2017.

OST, François. A natureza à margem da lei: a ecologia à prova do direito. Lisboa: Instituto Piaget, 1995.

POHLMANN, Patrícia; PICCININI, Lívia; DA SILVA FILHO, Luiz Carlos. Gerenciamento de riscos: Qual é o papel do planejamento urbano? Disponível em: <

https://www.academia.edu/13100428/GERENCIAMENTO_DE_RISCOS_QUAL_\%C3\%89_O_PAPEL_DO_PLANEJAMENTO_URBANO>. Acesso em: 20 ago. 2019.

POZZER, Camila Pinheiro; COHEN, Sinome Cynamon; COSTA, Francisco da Silva. O Marco de Ação Hyogo aplicado à gestão de risco de inundação no Brasil e em Portugal. Disponível em: < https://digitalis-dsp.uc.pt/bitstream/10316.2/35119/1/Territorium21_ artigo6.pdf? In=pt-pt >. Acesso em: 18 nov. 2017.

SÉGUIN, Élida. A lei da defesa civil: algumas considerações. Disponível em: <http://faa.edu.br/revistas/docs/RID/2012/RID_2012_14.pdf>. Acessoem: 18 set. 2016.

SIEBERT, Claudia. Mudanças Climáticas e Desastres Naturais em Santa Catarina: Impactos Socioterritoriais e Avaliação de Políticas Públicas. Disponível em:

<http://anpur.org.br/xviienanpur/principal/publicacoes/XVII.ENANPUR_Anais/ST_Sessoes_Tematicas/ST\%204/ST\%204.5/ST\%204.504.pdf>. Acesso em 13 Jun. 2017.

SOARES, Ana Paula Marcante. O Processo de Ambientalização e a Juridicização do Risco: Reflexões sobre a dimensão simbólica do direito ambiental. In: BENJAMIN, Antonio Herman; LECEY, Eladio; CAPPELLI, Silvia (Org.). Direito Ambiental, Mudanças Climáticas e Desastres:impactos nas cidades e no Patrimônio Cultural. São Paulo: Imprensa Oficial, 2009.

SUSTEIN, Cass R. Irreversibility. Law, Probability and Risk. V9, n3-4, 2010.

VALENCIO, Norma. et. al. Sociologia dos Desastres: Construções, Interfaces e Perspectivas no Brasil. São Carlos: Rima Editora, 2009.

VALENCIO, Norma; VALENCIO, Arthur. Cobertura Jornalística sobre Desastres no Brasil: Dimensões Sociopolíticas Marginalizadas no Debate Público. Disponível em:<

https://www.researchgate.net/publication/317811760_Cobertura_jornalistica_sobre_desastres_no_Brasil_dimensoes_sociopoliticas _marginalizadas_no_debate_publico >. Acesso em: 07 set. 2011.

VIEIRA, Ricardo Stanziola; CAVEDON, Fernanda de Salles. Conexões entre Desastres Ecológicos, Vulnerabilidade Ambiental e Direitos Humanos: Novas Perspectivas. In: BENJAMIN, Antonio Herman; LECEY, Eladio; CAPPELLI, Silvia (Org.). Direito Ambiental, Mudanças Climáticas e Desastres:impactos nas cidades e no Patrimônio Cultural. São Paulo: Imprensa Oficial, 2009.

VERCHICK, Robert. Disaster Justice: the geography of human capability. Disponível em:<http://scholarship.law.duke.edu/cgi/viewcontent.cgi?article=1238\&context=delpf>. Acesso em 14 jan. 2017.

UFSC, Universidade Federal de Santa Catarina. Centro Universitário de Estudos e Pesquisas sobre Desastres. Atlas Brasileiro de Desastres Naturais: 1991 a 2012 / Centro Universitário de Estudos e Pesquisas sobre Desastres. 2. ed. rev. ampl. - Florianópolis: CEPED UFSC, 2013.

XIMENES, Elisa Francioli; CARVALHO, Mauren Lopes de; FREITAS, Carlos Machado de. Vulnerabilidade Socioambiental, Redução de Riscos de Desastres e Construção da Resiliência- Lições do Território no Haiti e das chuvas fortes da Região Serrana, Brasil. Disponível em: <www.scielo.br/scielo.php?Script=sci_arttext\&pid=S1413-81232012000600021>. Acesso em 15 maio 2017. 